\title{
Microstructure and Mechanical Properties of Structural Metals and Alloys
}

\author{
Andrey Belyakov \\ Laboratory of Mechanical Properties of Nanostructured Materials and Superalloys, Belgorod State University, \\ Belgorod, 308015, Russia; belyakov@bsu.edu.ru; Tel.: +7-4722-585457 \\ Received: 27 August 2018; Accepted: 28 August 2018; Published: 29 August 2018 \\ check for \\ updates
}

\section{Introduction and Scope}

Mechanical properties of polycrystalline structural metals and alloys are significantly affected by their microstructures including phase content, grain/subgrain sizes, grain boundary distribution, dispersed particles, dislocation density, etc. The development of metallic materials with desired structural state results in beneficial combinations of mechanical properties. Specific alloying designs along with a wide variety of thermal, deformation, and many other treatments are used to produce metallic semi-products with favorable microstructures in order to achieve the required properties. Therefore, the studies on structure-property relationships are of a great practical importance. The aim of this special issue is to present the latest achievements in theoretical and experimental investigations of mechanisms of microstructural changes/evolutions in various metallic materials subjected to different processing methods and their effect on mechanical properties.

\section{Contributions}

The present special issue on the microstructure and mechanical properties of structural metals and alloys collects papers dealing with various aspects of microstructure-property relationships of advanced structural steels and alloys including commercial and novel materials. A total of 22 papers cover a ranger of structural metals and alloys. The major portion of these papers is focused on the mechanisms of microstructure evolution and the mechanical properties of metallic materials subjected to various thermo-mechanical, deformation, or heat treatments [1-12]. Another large portion of the studies is aimed on the elaboration of alloying design of advanced steels and alloys [13-16]. The changes in phase content, transformation, and particle precipitation and their effect on the properties are also broadly presented in this collection [17-21]. In two papers [19,22], particular emphasis is placed on the microstructure/property changes caused by irradiation.

Those readers interested in structural steels may learn much from comprehensive investigations of microstructural changes and their effect on mechanical properties caused by plastic working and heat treatment of diverse steel types $[2,7,8,10,12,15,16,19-22]$. Two of these papers $[7,12]$ present experimental/simulation results of mechanical behavior of high-Mn TWIP steels, which have recently aroused a great interest among material scientists and engineers because of outstanding strengthductility combination inherent in such steels. Some crucial features of structure-property relations are detailed for advanced heat resistant $[10,15,19,22]$ and stainless [8,21] steels. Materials scientists working with aluminum alloys may find many interesting results for dispersion strengthening, including processing, structural/precipitation analysis, and mechanical testing $[13,17,18]$. As a guest editor, I have the pleasure to note that present collection is not limited to such frequently used materials like steel and aluminum alloys. Interested readers will find attractive reports on magnesium [1], nickel [3], titanium [4,5], copper [6,11], and tin [14] alloys. Those who are interested in innovative materials, and their processing and applications, are suggested to take a good look at $\mathrm{Ti} / \mathrm{TiB}$ metal-matrix 
composite [5] and high-entropy alloys [9]. The great diversity of materials, which are presented in this special issue, involves various techniques of their production. Worthy of mention are severe plastic deformation $[5,9]$ and welding $[8,10]$ as topics of quickened interest. As a guest editor, I sincerely believe that every reader among materials scientists will find interesting and useful information in the present special issue.

\section{Conclusions and Outlook}

The papers collected in this special issue clearly reflect the modern research trends in materials science. These fields of specific attention are high-Mn TWIP steels, high-Cr heat resistant steels, aluminum alloys, ultrafine grained materials including those developed by severe plastic deformation, and high-entropy alloys. In spite of great effort in the development of advanced structural metals and alloys, these topics deserve further comprehensive investigations. The engineering and technology progress is closely related with the development of new structural materials with improved mechanical properties. This requires deep knowledge of mechanisms and regularities of microstructural changes during processing and exploitation, as well as clear understanding of microstructure-property relationships. No doubt, structural materials will continuously attract a great interest among materials scientists and engineers.

As a guest editor, I would like to thank all the authors for their valuable contribution to the present special issue; special thanks to the Metals editorial team, in particular to Ms. Hollie Huang, for their assistance and support during the preparation of this special issue.

Conflicts of Interest: The author declares no conflict of interest.

\section{References}

1. Che, C.; Cai, Z.; Cheng, L.; Meng, F.; Yang, Z. The Microstructures and Tensile Properties of As-Extruded Mg-4Sm-xZn-0.5Zr (x = 0, 1, 2, 3, 4 wt \%) Alloys. Metals 2017, 7, 281. [CrossRef]

2. Niu, G.; Wu, H.; Zhang, D.; Gong, N.; Tang, D. Study on Microstructure and Properties of Bimodal Structured Ultrafine-Grained Ferrite Steel. Metals 2017, 7, 316. [CrossRef]

3. Underwood, O.D.; Madison, J.D.; Thompson, G.B. Emergence and Progression of Abnormal Grain Growth in Minimally Strained Nickel-200. Metals 2017, 7, 334. [CrossRef]

4. Li, K.; Yang, P. The Formation of Strong $\{100\}$ Texture by Dynamic Strain-Induced Boundary Migration in Hot Compressed Ti-5Al-5Mo-5V-1Cr-1Fe Alloy. Metals 2017, 7, 412. [CrossRef]

5. Zherebtsov, S.; Ozerov, M.; Stepanov, N.; Klimova, M.; Ivanisenko, Y. Effect of High-Pressure Torsion on Structure and Microhardness of Ti/TiB Metal-Matrix Composite. Metals 2017, 7, 507. [CrossRef]

6. Wang, H.; Huang, H.; Xie, J. Effects of Strain Rate and Measuring Temperature on the Elastocaloric Cooling in a Columnar-Grained Cu71Al17.5Mn11.5 Shape Memory Alloy. Metals 2017, 7, 527. [CrossRef]

7. Kalinenko, A.; Kusakin, P.; Belyakov, A.; Kaibyshev, R.; Molodov, D.A. Microstructure and Mechanical Properties of a High-Mn TWIP Steel Subjected to Cold Rolling and Annealing. Metals 2017, 7, 571. [CrossRef]

8. Nam, T.H.; An, E.; Kim, B.J.; Shin, S.; Ko, W.S.; Park, N.; Kang, N.; Jeon, J.B. Effect of Post Weld Heat Treatment on the Microstructure and Mechanical Properties of a Submerged-Arc-Welded 304 Stainless Steel. Metals 2018, 8, 26. [CrossRef]

9. Zherebtsov, S.; Stepanov, N.; Ivanisenko, Y.; Shaysultanov, D.; Yurchenko, N.; Klimova, M.; Salishchev, G. Evolution of Microstructure and Mechanical Properties of a CoCrFeMnNi High-Entropy Alloy during High-Pressure Torsion at Room and Cryogenic Temperatures. Metals 2018, 8, 123. [CrossRef]

10. Liu, X.; Cai, Z.; Yang, S.; Feng, K.; Li, Z. Characterization on the Microstructure Evolution and Toughness of TIG Weld Metal of 25Cr2Ni2MoV Steel after Post Weld Heat Treatment. Metals 2018, 8, 160. [CrossRef]

11. Chen, X.; Jiang, F.; Jiang, J.; Xu, P.; Tong, M.; Tang, Z. Precipitation, Recrystallization, and Evolution of Annealing Twins in a Cu-Cr-Zr Alloy. Metals 2018, 8, 227. [CrossRef]

12. Torganchuk, V.; Glezer, A.V.; Belyakov, A.; Kaibyshev, R. Deformation Behavior of High-Mn TWIP Steels Processed by Warm-to-Hot Working. Metals 2018, 8, 415. [CrossRef] 
13. Morozova, A.; Mogucheva, A.; Bukin, D.; Lukianova, O.; Korotkova, N.; Belov, N.; Kaibyshev, R. Effect of Si and $\mathrm{Zr}$ on the Microstructure and Properties of Al-Fe-Si-Zr Alloys. Metals 2017, 7, 495. [CrossRef]

14. Park, Y.; Bang, J.H.; Oh, C.M.; Hong, W.S.; Kang, N. The Effect of Eutectic Structure on the Creep Properties of Sn-3.0Ag-0.5Cu and Sn-8.0Sb-3.0Ag Solders. Metals 2017, 7, 540. [CrossRef]

15. Fedoseeva, A.; Dudova, N.; Kaibyshev, R.; Belyakov, A. Effect of Tungsten on Creep Behavior of $9 \% \mathrm{Cr}-3 \% \mathrm{Co}$ Martensitic Steels. Metals 2017, 7, 573. [CrossRef]

16. Chu, R.; Fan, Y.; Li, Z.; Liu, J.; Yin, N.; Hao, N. Study on the Control of Rare Earth Metals and Their Behaviors in the Industrial Practical Production of Q420q Structural Bridge Steel Plate. Metals 2018, 8, 240. [CrossRef]

17. Ma, P.; Jia, Y.; Gokuldoss, P.K.; Yu, Z.; Yang, S.; Zhao, J.; Li, C. Effect of Al2O3 Nanoparticles as Reinforcement on the Tensile Behavior of Al-12Si Composites. Metals 2017, 7, 359. [CrossRef]

18. He, H.; Zhang, L.; Li, S.; Wu, X.; Zhang, H.; Li, K. Precipitation Stages and Reaction Kinetics of AlMgSi Alloys during the Artificial Aging Process Monitored by In-Situ Electrical Resistivity Measurement Method. Metals 2018, 8, 39. [CrossRef]

19. Yang, Z.; Jin, S.; Song, L.; Zhang, W.; You, L.; Guo, L. Dissolution of M23C6 and New Phase Re-Precipitation in Fe Ion-Irradiated RAFM Steel. Metals 2018, 8, 349. [CrossRef]

20. Muro, M.; Artola, G.; Gorriño, A.; Angulo, C. Effect of the Martensitic Transformation on the Stamping Force and Cycle Time of Hot Stamping Parts. Metals 2018, 8, 385. [CrossRef]

21. Paulsen, C.O.; Broks, R.L.; Karlsen, M.; Hjelen, J.; Westermann, I. Microstructure Evolution in Super Duplex Stainless Steels Containing $\sigma$-Phase Investigated at Low-Temperature Using In Situ SEM/EBSD Tensile Testing. Metals 2018, 8, 478. [CrossRef]

22. Li, Q.; Shen, Y.; Zhu, J.; Huang, X.; Shang, Z. Evaluation of Irradiation Hardening of P92 Steel under Ar Ion Irradiation. Metals 2018, 8, 94. [CrossRef]

(C) 2018 by the author. Licensee MDPI, Basel, Switzerland. This article is an open access article distributed under the terms and conditions of the Creative Commons Attribution (CC BY) license (http:/ / creativecommons.org/licenses/by/4.0/). 